\title{
Effects of framing and mathematical experience on judgments
}

\author{
WING HONG LOKE and STELLA LI LING LAU \\ National University of Singapore, Singapore
}

\begin{abstract}
The effects of framing and mathematical training on judgment were investigated. Pre-university students with either little or advanced training in mathematics were tested on their responses to a series of decision-making scenarios. They indicated their likelihood of accepting strategies when given information that was framed either positively or negatively. As expected, positively framed strategies received higher likelihood ratings than their negatively framed equivalent. Of note is that nonmathematically trained students produced higher likelihood ratings than did mathematically trained students. However, the interaction between framing and mathematical training was not significant. This suggests that while mathematically trained individuals were less willing to accept the strategies, they were just as influenced by framing as the nonmathematically trained individuals were. Discussions focus on possible differences in framing effects based on levels of expertise in judgment, simulated versus real decision-making tasks, and, particularly, the content (i.e., cognitive vs. affective nature) of the decision-making tasks.
\end{abstract}

Studies have shown that the way information is presented or framed can affect our judgment (Kahneman \& Tversky, 1979; Tversky \& Kahneman, 1981). For example, purchases of ground beef were judged more favorably when the beef was described in terms of its "percentage lean" rather than "percentage fat;"' even though the objective information (i.e., the amount of fat/lean in the beef) was the same in each case (Levin \& Johnson, 1984). Furthermore, according to prospect theory (Kahneman \& Tversky, 1979), the value function describing the subjective worth of outcomes of a gamble or prospect is assumed to be steeper for losses than for gains. One interpretation is that the displeasure with losses is greater than the pleasure associated with gains of the same amount.

An alternative interpretation for the asymmetric value function could be that negative relationships between variables are more difficult to learn than positive relationships (Slovic, 1974). This interpretation implies that both positive and negative relationships between variables can be learned. As shown by Larrick, Morgan, and Nisbett (1990), although naive individuals are not rational by economists' standards, brief training for these individuals could improve their solutions to hypothetical economic problems.

Hence, given that statistical reasoning can be improved by training, we examined whether a similar domain, such as mathematical training, could reduce the effects of framing. Instead of developing a brief mathematical training program, we chose to compare performance between individuals who had received extended mathematical train-

Address correspondence to W. H. Loke, Department of Social Work and Psychology, 10 Kent Ridge Crescent, National University of Singapore, Singapore 0511 . ing and those with little or no similar training. Given the educational curriculum in Singapore, we were able to select pre-university students who either had an educational curriculum in mathematics or had no mathematics in their curriculum. Mathematics, as noted in several dictionaries, uses defined literal, numerical, and operational symbols to study numbers, form arrangements, and associated relationships. The characteristics of mathematics are analogous to the elements of numbers and to the processing of numbers in the present decision-making task.

The present study examined whether individuals with a mathematical background would be less affected by framing on a decision-making task than individuals without a mathematical background. Such a comparison is analogous to the use of experts versus novices, as discussed by Loke and Tan (1991) in their study of the influences of framing on expertise.

\section{METHOD}

\section{Subjects}

Sixty-four pre-university students from a junior college $(M=17$ years; $S D=0.23$ years) participated. Half of the students were from a science curriculum and the other half were from an arts curriculum; an equal number of males and females were in each group. Individuals from the arts background were taught only elementary mathematics and had not received any mathematical training during the previous year. The sciencebackground students had been taught general mathematics and further (advanced) mathematics.

\section{Materials}

A booklet containing 30 hypothetical scenarios, with each of 15 unique scenarios repeated once, was used. The first page of each booklet contained requests for the subjects' biographical data such as age, gender, and current training in mathematics. The second page contained general instructions for the task; it was followed by $\mathbf{3 0}$ randomly arranged pages of hypothetical scenarios (one situation per page). Each situation focused on one of three decisions: (1) purchase of hamburger patties, (2) closure of company's branch units, and (3) attempt to make an emer- 
Table 1

Typical response structure, illustrating stimulus presentation and response scales, of a postive framing situation

A normal hamburger patty, made up of meat and fat, weighs 50 grams. What is the likelihood that you will purchase the patty if it contains 35 grams of meat?

Your response (check one):

Very unlikely to purchase

Quite unlikely to purchase

Somewhat unlikely to purchase

Equally likely or unlikely to purchase

Somewhat likely to purchase

Quite likely to purchase

Very likely to purchase

gency landing. Table 1 shows an example: the negative framing situation would read " 15 grams fat" instead of "35 grams meat."

\section{Pilot study}

The task booklet was tested on 12 students to ensure that the situations could be understood and that framing would exist. The results for this pilot study showed that the mean ratings were 0.52 and -0.25 for the positive and negative framing scenarios, respectively. No inferential statistics were used, due to the small sample size.

\section{Procedure}

The subjects were presented with the task booklets and were asked to evaluate the likelihood of accepting each situation on a 7-point scale. In general, the subjects took $20 \mathrm{~min}$ to complete the booklet. After completion, they were thanked and debriefed.

\section{RESULTS}

An analysis of variance was used to examine the likelihood ratings of accepting the strategies of the scenarios. The main independent variables examined were framing (positive and negative framing scenarios) and amount of prior training in mathematics (science and arts backgrounds). Gender was also analyzed as a secondary independent variable, but there was no significant effect.

The subjects provided higher likelihood ratings in the positive $(M=0.49)$ than in the negative framing scenarios $[M=-0.10 ; F(1,60)=59.95, p<.05]$. The artsbackground subjects showed higher likelihood ratings (greater willingness; $M=0.37$ ) than the science-background subjects did in accepting the scenarios $[M=0.25$; $F(1,60)=6.73, p<.05]$. The predicted two-way interaction of framing and training was not significant $[F(1,60)=0.66]$.

\section{DISCUSSION}

In agreement with past studies (Levin \& Johnson, 1984; Loke, 1989; Tversky \& Kahneman, 1981), the present results showed a significant framing effect. Positively framed scenarios produced more favorable ratings than the same situations that were framed negatively.

It is interesting that individuals with little mathematical training had higher likelihood ratings than those with significant mathematical training. However, the interaction between framing and training was not significant. So, although mathematically trained individuals were less willing to accept the scenarios, they were as influenced by framing as nonmathematically trained individuals. Perhaps the regular use of numerical values in decision making by mathematically trained individuals made them more cautious, or conservative, in their ratings. But even with mathe- matical training they were affected by framing in the present decisionmaking task, which required only addition and subtraction.

The view that experts' judgments and decisions can be influenced by framing has been observed in several past studies (von Holstein, 1972; Loke \& Tan, 1991; Rybash \& Roodin, 1989). In the present study, we used pre-university students whose backgrounds were either in arts or in science. It is possible that these students could have been selected several years ago into their respective curricula on factors such as interests and aptitude, and this, therefore, may have affected the framing effect induced in the present study. If so, experts (graduates in mathematics) should also be examined. Loke and Tan (1991), who compared finance experts (professors and third-year business administration undergraduates) with first-year nonfinance (psychology) undergraduates, found that all of their subjects were affected by the framing effect on hypothetical gamble scenarios. However, Loke and Tan did mention that the definition of expertise could be even more stringent than it was in their study. For example, Phelps and Shanteau (1978) examined hypothetical quality assessments of breeding by expert livestock judges in terms of 11 dimensions (e.g., body weight and ham thickness) crucial for breeding. Their results showed that the judges made decisions that were reliably influenced by the 11 dimensions. As proposed by Shanteau (1988), there are experts, novices, and naive decision makers-experts have reached the pinnacle of their profession, novices have knowledge and experiences but have yet to reach a level of expertise, and naive decision makers have little, if any, decisionmaking skills in a given area.

Rybash and Roodin (1989) discovered that physicians made decisions, such as whether to opt for risky treatment, depending on whether the treatment was expressed in terms of "number of lives saved" (positively framed) or "number of lives lost" (negatively framed). Perhaps using real situations would reduce the framing effect on experts from that produced by the simulated scenarios used in the present study. But von Holstein (1972), who compared the forecasts of investment bankers, stock market experts, business administration teachers, and students on their accuracy in estimating future prices in the stock market, found that no group showed any significantly accurate prediction. Other similar studies on the performance of mutual funds showed that professionally managed portfolios do not consistently outperform the market average (e.g., Fabozzi \& Francis, 1979; Fama, 1965), suggesting that experts are susceptible to judgmental biases. Several researchers (Levin et al., 1988; Lichtenstein \& Slovic, 1973) have shown that a simulated task is a valid predictor of behavior outside the laboratory setting.

The focus in the future, then, could be on the content of decisionmaking tasks. The present decision-making task, as in most other studies, consists of a "cognitive set of events," in contrast to tasks that may evoke judgments based on emotions (affective-content tasks). In this regard, an interesting contention is that both experts and novices may be similarly affected by framing for cognitive-content tasks, but experts may be less influenced by framing in affective-content tasks than are novices.

As a generalization, both past and present studies show that framing can lead to judgmental biases. This understanding could be used by particular groups of individuals such as advertisers and negotiaters to affect a change in the behavior of individuals toward varying information, even though the objective information remains the same. For example, supermarkets could use "percentage lean" on their product labels, or, in labor negotiations (Neale \& Bazerman, 1985), could induce a positive frame that leads to a decision aimed at seeking gains, or could induce a negative frame that leads to a decision that avoids losses.

\section{REFERENCES}

FabOzZI, F. J., \& Francis, J. C. (1979). Mutual fund systematic risk for bull and bear markets. Journal of Finance, 34, 243-250.

FAMA, E. F. (1965). The behavior of stock market prices. Journal of Business, 38, 34-105.

HoLsteIn, S. von (1972). Probabilistic forecasting: An experiment related to the stock market. Organizational Behavior \& Human Performance, 83, 139-158.

Kahneman, D., \& Tversky, A. (1979). Prospect theory: An analysis of decision under risk. Econometrica, 47, 263-291.

Larrick, R. P., Morgan, J. N., \& Nisbett, R. E. (1990). Teaching 
the use of cost-benefit reasoning in everyday life. Psychological Science, 1, 362-370.

Levin, I. P., Chapman, D. P., \& Johnson, R. D. (1988). Confidence in judgments based on incomplete information: An investigation using both hypothetical and real gambles. Journal of Behavioral Decision Making, 1, 29-41.

LeVIN, I. P., \& Johnson, R. D. (1984). Estimating price-quality tradeoffs using comparative judgments. Journal of Consumer Research, 11, 593-600.

Lichtenstein, S., \& SLovic, P. (1973). Response-induced reversals of preference in gambling: An extended replication in Las Vegas. Journal of Experimental Psychology, 101, 16-20.

LOKE, W. H. (1989). The effects of framing and incomplete information on judgment. Journal of Economic Psychology, 10, 329-341.

LOKE, W. H., \& TAN, K. F. (1991). Effects of framing and missing information in expert and novice judgment. Bulletin of the Psychonomic Society, 30, 187-190.

Neale, M. A., Bazerman, M. H. (1985). The effect of framing and negotiation over confidence in bargaining behavior and outcomes. Academy of Management Journal, 28, 34-39.

Phelps, R. H., Shanteau, J. (1978). Livestock judges: How much information can an expert use? Organizational Behavior \& Human Performance, 21, 209-219.

Rybash, J. M., Roodin, P. A. (1989). The framing heuristic influences judgments about younger and older adults' decisions to refuse medical treatment. Applied Cognitive Psychology, 3, 171-180.

Shanteau, J. (1988). Psychological characteristics and strategies of expert decision makers. Acta Psychologica, 68, 203-215.

SLovic, P. (1974). Hypothesis testing in learning of positive and negative linear functions. Organizational Behavior \& Human Performance, 11, 368-376.

TVersky, A., Kahneman, D. (1981). The framing of decisions and the psychology of choice. Science, 211, 453-458.

(Manuscript received April 20, 1992.) 